\title{
Penile Fracture by Dog Bite in Children: A Case Report
}

\section{Nandiolo KR*, Lohourou Grah F, Kpangni JB and Traoré I \\ Resident, pediatric surgery, teaching hospital of Bouaké, Côte d'Ivoire}

*Corresponding author: Nandiolo Koné Rose, Professor, Pediatric surgery department, University alassane Ouattara of Bouaké, Côte d'Ivoire, Catholic hospital St Joseph Moscati of Yamoussoukro, Côte d'Ivoire, Tel: +225 07076139; Email: fleur1us@yahoo.com

\section{Case Report}

Volume 3 Issue 4

Received Date: November 26, 2018

Published Date: December 26, 2018

DOI: $10.23880 / o a j u n-16000151$

\section{Abstract}

We report a case of ten years old boy with external genitalia trauma by dog bite. The boy was running when he hit the neighbor's unrestrained dog which was sleeping outdoors. The child presented with urinary retention with penile injuries. We performed a vesicostomy followed two days later, by a surgical exploration of injuries. We noticed a fracture of the penis with a concomitant complete disruption of penile urethra. We performed debridement, realignment of urethra by catheterization of proximal and distal urethra; then, urethra and the corpus cavernosum were reconstructed. Tetanus and rabies immunization has been done. The follow up was uneventful with normal voiding and no erectile dysfunction four (4) years later.

Background: Genitalia dog bite is rare. Injuries varied from moderate skin loss to severe injuries like complete penile and scrotal avulsion [1] which can lead to genital feminization or genital reconstruction. Penile fracture is the traumatic rupture of the corpus cavernosum associated most of the time with sexual intercourse in adult, and trauma in children [24]. The goal of this study was to report our experience of a rare case of penile fracture in children by a dog bite and discuss the management.

Conclusion: Early surgical exploration, debridement and primary reparation of penetrating injuries are advised in male children with external genitalia dog bites. Realignment by the catheterization of proximal and distal urethra prevents extensive mobilization of urethra with good result, in case of complete urethral disruption, especially when endoscopy is not available.

Keywords: Children; Dog bite; Genitalia; Penile fracture; Urethra

\section{Case Report}

A 10 years old boy was referred by surgical emergency unit, one day after a trauma of the external genitalia by dog bite. The child was attacked when he accidentally hit and fell onto an unrestrained dog belonging to his neighbour. This dog was sleeping outdoors. The symptoms included urinary retention, penile swelling, suprapubic and scrotal edema (Figure 1A), uretrorragy, and bleeding. Clinical examination revealed a patient with 
a good general status, weighing $25 \mathrm{~kg}$, haemodynamically stable, blood pressure was $110 \mathrm{~mm} / 70 \mathrm{Hg}$ and heart rate 104 pulse/minute. The respiratory frequency was 26 cycles/minute. External genitalia examination founded out a curved and twisted penis lying on the pubis by the dorsal side, with blood at meatus, one linear penetrating ventral and lateral wound, and superficial wounds $(0,5 \mathrm{~cm}$ to $1 \mathrm{~cm}$ ) (Figure 1B). The blood cell count was normal with a hemoglobin level of $11.5 \mathrm{~g} / \mathrm{dl}$. An emergent vesicostomy was performed and he underwent 2 days later, a surgical repair under general anesthesia. Surgical exploration has been done through longitudinal penoscrotal incision over the penetatring penile wound. We noticed a unilateral rupture of ventral and right corpus cavernosum (Figure 2) with a complete disruption of penile urethra (Figure 3). We achieved a debridement, irrigation of the injuries with saline providone-iodine solution and the hemostasis, before proceeding to a realignment of urethra using a $\mathrm{CH} 10$ Foley catheter through combine supra pubic (vesicostomy hole) and trans urethral approaches. Then, urethra and corporeal body (corpus cavernosum) were reconstructed with interrupted absorbable 4-zero polyglycolic acid sutures. We closed vesicostomy with urinary diversion by cystostomy catheter. He received post operatively ceftriaxone $2 \mathrm{~g}$ IV per day, gentamicin $100 \mathrm{mg}$ IM per day during 5 days, ketoprofen $60 \mathrm{mg}$ two times per day, paracetamol $400 \mathrm{mg}$ four times per day by infusion, and then amoxicillin - clavulanate per month during 21 days. Tetanus and rabies immunization had been done. Tetanus toxoid was also given. He was discharged from hospital at day 35 after removal of cystostomy and urethral catheters. After a four years follow up, the outcome was uneventful with normal voiding (Figure 4), absence of stenosis, and normal erection.
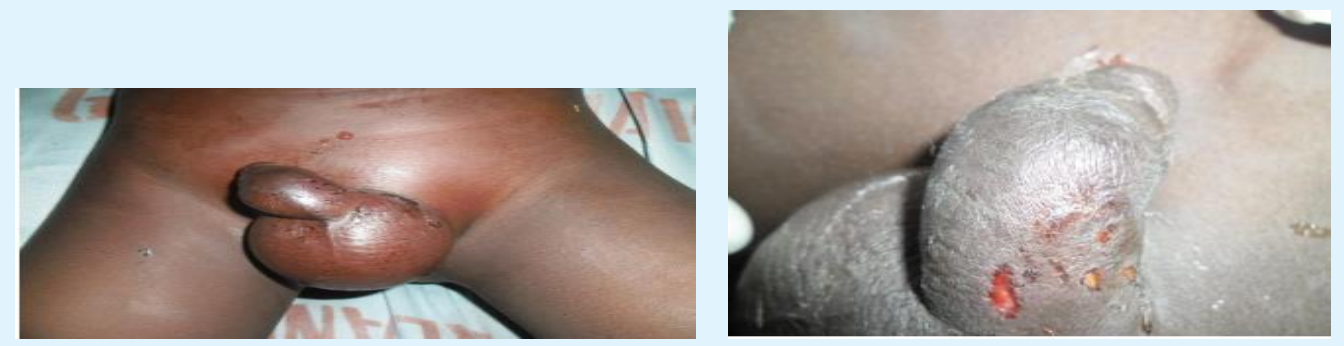

Figure 1A \& 1B: Trauma of external genitalia with perineum edema and penile wounds.

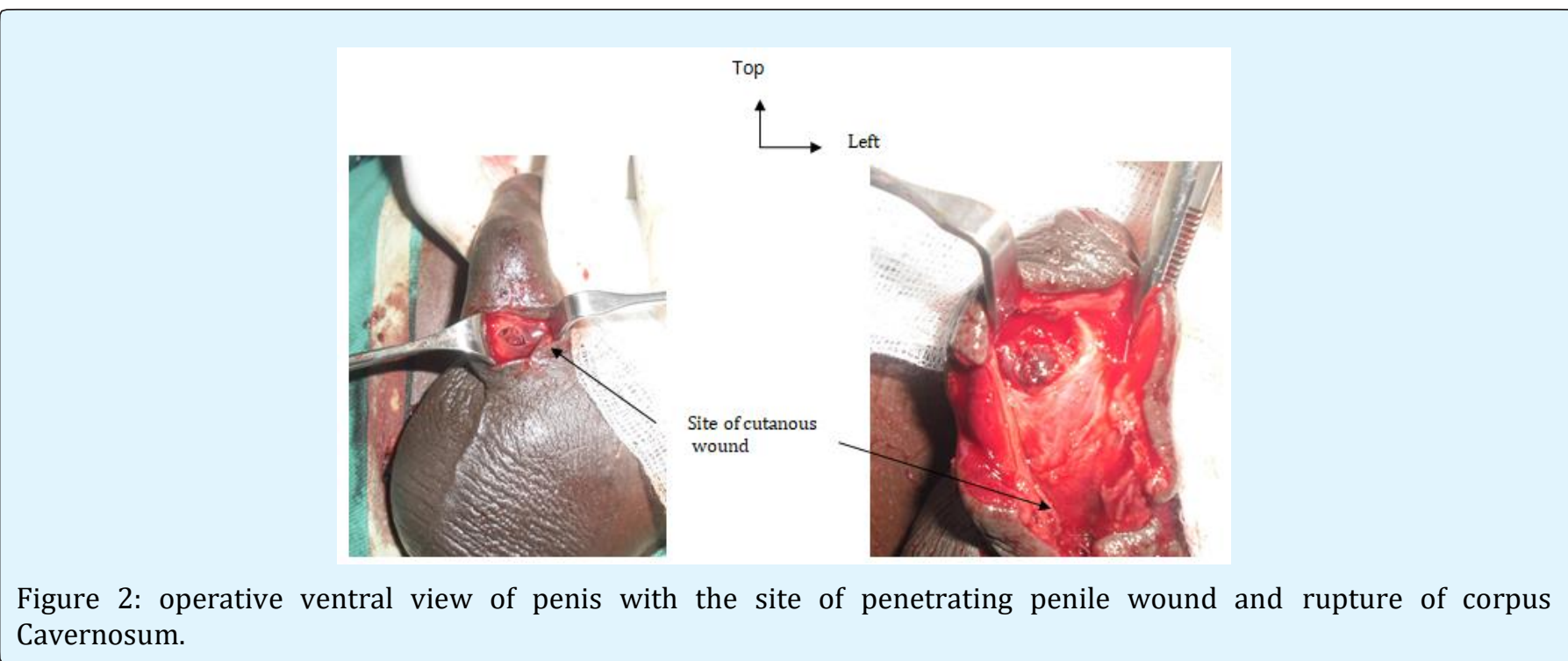



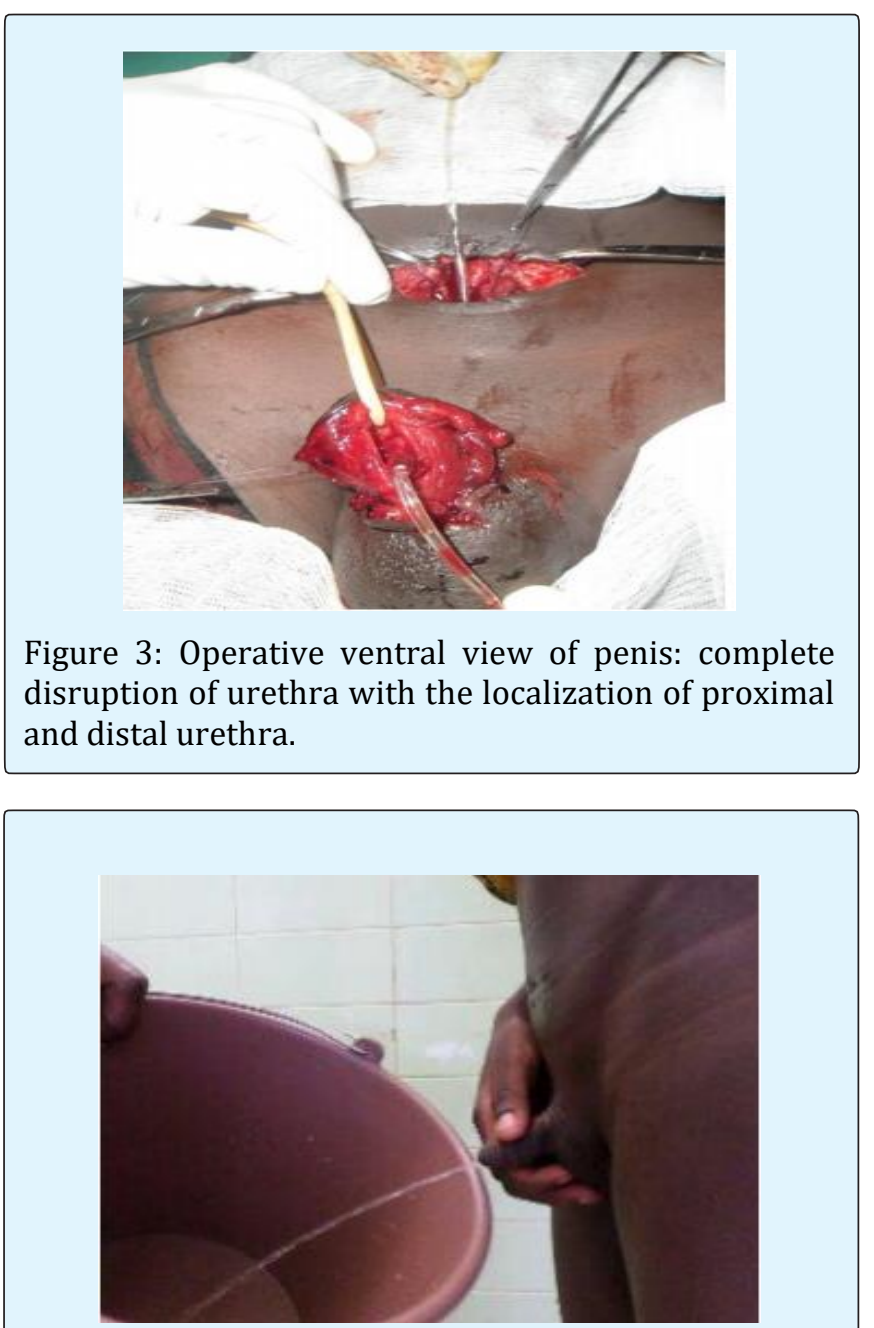

Figure 4: Results four years later: good urinary stream.

\section{Comments}

Children are the most common victims of dog bites $[1,5,6]$. The annual was 0.5 per 1000 children between 0 and 16 years of age in Schalamon's series; however, animal bite is a rare and severe cause of genital trauma $[1,5,7]$.

Dogs are familiar to children [7]. The dog belonged to the neighbor of our patient but in our conditions, it is frequently impossible to decide if a free roaming dog belongs to someone or not. Furthermore, in rural area like where our patient live, children use to play in the street without the presence of adult. They can also be injured by street Dog.

In developing countries, street dog population is high with poor housing facility while in developed country, children and dogs tend to play outside on warm, summer days $[6,7]$.

Dog is usually disturbed or startled while sleeping or while eating because Children tend to underestimate the danger arising from dogs and being more careless than adults in their interaction with dogs [6,7]. Running past dogs can also trigger an attack [7].

Penile fracture by dog bite is rare; reported injuries are usually very severe ranging from penile wound or penile degloving to partial or complete avulsion of the penis $[1,8]$. Leung reported a less severe case of dog bite wounds to the penis in 16-year-old boy [9]. Without rupture of corpus cavernosum or urethral disruption. In the flaccid state, injury to the penis is rare because of the mobility and flexibility of the organ and lesions are complicated by soft tissue (skin, subcutaneous, corporeal, and urethral) contusion, rather than fracture [3]. The transversal state of rupture of the corpus cavernosum and the fact that the site of the penetrating penile wound (Figure 1) was different from the site of this rupture (Figure 2), suggest that the penis of our patient was in erected position at the moment of the accident [10].

At clinical examination, post traumatic severe pain, swelling of the penis, urinary retention and blood at meatus suggested fracture of the penis with urethral damage. According to European Association of Urology, blood at the meatus is associated with urethral injury, and urethral instrumentation should be avoided until the urethra is imaged [8]. Further investigations were not indicated in the case of penile fracture with penetrating injuries we observed. Emergent surgery is the gold standard in urethral exploration and the reparation of corpus cavernosum $[8,10,11]$. In dog bite injuries, surgical management involves debridement and copious wound irrigation with saline providone-iodine solution or saline solution, suture of wounds and surgical reconstruction $[1,5,9]$. We performed an emergent vesicostomy in absence of supra pubic catheter which is a simple, fast and effective procedure for urinary diversion. Surgical exploration has been done through a longitudinal penoscrotal incision over the largest penile wound. Most of authors advised a complete penis degloving through a circumferential sub coronal incision to provide the exploration of a larger part of the penis and complete mobilization of proximal and distal urethra [8]. For the others, that can lead to nervous and vascular risk with erectile dysfunction and subsequent skin necrosis because of extensive dissection [2]. The alignment of urethra through supra pubic (vesicostomy or endoscopy) and transurethral approaches could reduce the vascular 
risk by providing minimal dissection. The early and carefully reconstruction of corpus cavernosum avoid the risk of fibrosis with erectile dysfunction. Urethral catheter is left 15-21 days [8]. At 10 days to 2 weeks, a cystourethrogram should be obtained with the urethral catheter in situ. If there is no leakage at the anastomotic site, the urethral catheter can be removed; [8]. As parent could not efford to pay for the cystourethrogram at day 15 , we left catheter until day 35 . Tetanus and rabies are the most serious conditions transmitted via dog bite [5]. Prompt medical care included antibiotic prophylaxis, tetanus has been done as recommended, to prevent infectious complications [1,8]. The dog was not vaccinated. The patient lived at more than $100 \mathrm{Km}$ from our hospital, so we recommended to the owner (by phone) to send the dog to the health institute for further investigations. Tetanus toxoid only should be given to those who previously completed the primary immunization series but who have not received a booster for more than 5 years [8]. For the patients who had not been previously immunized or where the last known immunization was received more than 10 years before the injury, human tetanus immunoglobulin should be added [12].

\section{Conclusion}

Early surgical exploration, debridement and primary reparation of penetrating injuries are advised in male children with external genitalia dog bites. Realignment by the catheterization of proximal and distal urethra prevents extensive dissection of urethra with good result, in case of complete urethral disruption.

\section{References}

1. Gomes CM, Ribeiro-Filho L, Giron AI, Mitre AI, Figueira ERR, et al. (2001) Genital trauma due to animal bites. J Urol 165(1): 80-83.

2. Mansi MK, Emran M, el-Mahrouky A, el-Mateet MS (1993) Experience with penile fractures in Egypt: long-term results of immediate surgical repair. J Trauma 35(1): 67-70.

3. Gruenberg BC, Mortel D, Bogie A (2018) Rupture of the Corpus Cavernosum in a Pediatric Patient. Pediatr Emerg Care Jun 14.

4. Zare S, Hashemi M (2017) Pediatric penile fracture with severe urethral disruption: A rare case presentation. Journal of Case Reports in Practice (JCRP) 5(2): 15-17.

5. Bertozzi M, Appignani A (2013) The management of dog bite injuries of genitalia in paediatric age. Afr J Paediatr Surg 10(3): 205-210.

6. Bothra R, Bhat A, Saxena G, Chaudhary G, Narang V (2011) Dog bite injuries of genitalia in male infant and children. Urol Ann 3(3): 167-169.

7. Schalamon J, Ainoedhofer H, Singer G, Petnehazy T, Mayr J, et al. (2006) Analysis of Dog Bites in Children Who Are Younger Than 17 Years. Pediatrics 117(3): 374-379.

8. Martínez-Piñeiro L, Djakovic N, Plas E, Mor Y, Santucci RA, et al. (2010) EAU Guidelines on Urethral Trauma. Eur Urol 57(5): 791-803.

9. Leung AK, Robson WL (2005) Penile dog bite in an adolescent. Advances in Therapy 22(4): 363-367.

10. Nale Dj, Nikić P, Vuković I, Djordjević D, Vuksanović A (2008) Surgical or conservative treatment of penile fracture. Acta Chir Iugosl 55(1): 107-114.

11. Manunta A, Vincendeau S, Patard JJ, Lobel B, Guillé F (2004) Traumatismes récents de l'urètre masculin in techniques chirurgicales urologie. Encycl Méd-Chir 41-330.

12. Fleisher GR (1999) The management of dog bite wounds. New Eng J Med 340(2): 138-140. 